\title{
Violence against Teachers in Jordanian Schools
}

\author{
Dr. Mohammad Sayel Alzyoud \\ Associate Professor of Educational Studies, Department of Educational \\ Administration and Foundations, Faculty of Educational Sciences, \\ The University of Jordan, Amman, Jordan.
}

\section{Dr. Ali Salem Al-Ali}

Associate Professor of Linguistics, Department of European Languages, Faculty of Foreign Languages, The University of Jordan, Amman, Jordan

\section{Dr. Atif O. Bin Tareef}

Associate Professor of Educational Administration, Department of Educational Administration and Foundations, Faculty of Educational Sciences, The University of Jordan, Amman, Jordan

\section{doi: 10.19044/esj.2016.v12n10p223 URL:http://dx.doi.org/10.19044/esj.2016.v12n10p223}

\begin{abstract}
This aim of this study is to examine the reasons for violence against teachers in Jordan from the perspective of high school students. The study followed a qualitative research approach by interviewing (50) students from grade twelve. Students were recruited in this study via the convenience sampling approach. The study revealed that teachers, school administration, school environment, media, and family conditions, were the major causes of student's violence against teachers. Teachers who experienced violence from students are the cause of this violence due to their actions and practices. Teachers are often exhausted, dispassionate, and overloaded with teaching and administrative duties. As a result, these duties sometimes hinder them not to communicate with students nicely or help students in solving their problems. Other times, students are violent against teachers because some teachers have low academic and educational performances. They are unable to offer counselling and psychological support to students from certain backgrounds. Subsequently, some students lack proper morals and discipline. School administrators are to be held responsible for the violence against teachers because they are unable to meet the students' needs.
\end{abstract}

Keywords: Jordan, parents, schools, teachers, violence 


\section{Study Background}

Jordan is one of the Middle East countries which are considered to be safe and secure. Hence, this was despite the country's lack of national resources. In the last twenty years, there have been so many changes in the characteristics of Jordanian society at the individual and collective levels in various aspects of life. Due to globalization, Jordan's society changed from a conservative, classical, and tribal society to an open society (Alzyoud, 2009). Many negative features of this change became part of Jordanian society. Thus, these features include social violence, the phenomena of pride and showing off among Jordanians, the presence of new consumer values, the dominance of a culture of consumption, and spending more on luxuries rather than on the basic needs of life.

The phenomenon of violence affects the stability of the society, and is one of the main challenges to the public and authorities. Subsequently, violence occurs as a result of the recent huge social and cultural changes imposed by internal and external factors. For instance, Jordan has received several massive waves of refugees due to the Palestinian issue since 1948, the first Gulf War in 1991, the collapse of the Iraqi regime in 2004, the conflict in Syria since 2011, and the Libyan and Yemeni crises, resulting to more than four million people been added to the teaming population in Jordan. However, these refugees were from different social and cultural backgrounds that negatively affected the stability of the Jordanian society and natural development. Furthermore, with Jordan's limited natural rescores, weak economy, globalization, social media, and full access to different online sources, violence has increased rapidly. In addition, the issue of violence issue is traceable to the different social, cultural, economic, and political changes that affected Jordanian society.

Violence is not limited to social or family organizations, it is mixed. Hence, it includes tribal violence, collective violence, and bullying (DAMRA \& GHBARI, 2014). The violence that affects Jordanian society is divided into two types: physical, emotional, or verbal violence that affects human personalities and violence that affects property and belongings. Furthermore, violent crime rate has increased rapidly over the past few years, strongly affecting human lives, properties, and belongings.

Violence, in fact, is a great problem that has existed since mankind came into existence. Therefore, since 1990, violence has increased in both developed and developing countries and has become a major public health problem (Gokler, Arslantas, \& Unsal, 2014). Violence and conflict takes place in many countries, issuing from inside society based on cultural, political, social, ethnical, or religious reasons or from outside society due to politics, security, cultural (in) tolerance, or economics (Al-Zyoud, Morgan, \& Brown, 2013). 
As a matter of fact, violence is a multifaceted matter associated with individual thoughts, attitudes, and behaviours. Therefore, several factors can influence the occurrence or non-occurrence of violence, which includes biological, psychological, social, cultural, economic, and political factors (Hijazi, 2009).

Violence is one of the main problems of contemporary societies. Social, cultural, economic, and environmental factors play a role in the formation of violence. Violence exists as an instinctive behaviour and is believed to arise from environmental factors (Tutkun \& Harman, 2011). In England and Wales, 23 percent of women and 15 percent of men aged 16 to 59 were reported to have been assaulted by a current or former partner at some point in their lives (Ghate, 2000).

Violence is a social problem that emerges for many reasons. Violence is practiced by people who have limited knowledge, communication skills, understanding, tolerance, respect, and peaceful thinking. Violence is practised mostly against certain groups in societies, specifically children, women, and by some professionals, like teachers, nurses, and doctors.

Violence in schools has increased in all countries (Tutkun \& Harman, 2011). School violence is something that takes place at school and in other places connected with school life (Kowzan, 2009). Therefore, violence in the school is a reflection of violence in the society (ALAIN, 2000).

Violence in schools is a challenging problem for educational systems, societies, and governments. Violence in schools includes: insults; threats; aggression against teachers and the administrative staff by pupils, parents, and friends of pupils; fistfights among youth; throwing stones, teargas bombs or even Molotov cocktails; and vandalism against the institution (classroom equipment) or against teachers (cars, theft, rackets, drugs, and alas, murder). The list is long but not exhaustive, and it only provides headlines for a media that is hungry for sensationalism (ALAIN, 2000).

School violence has emerged as a significant public health crisis that warrants immediate attention. Nationally, $11 \%$ of high school students report being in a fight, $8 \%$ report being threatened or injured with a weapon on school property, and $6 \%$ report carrying a weapon on school property in the past 30 days (McMAHON et al., 2014).

Consequently, a lot has been stated about bullying behaviour. Bullies have aggressive personalities and receive attention because of their violent behaviour. They come from troubled family situations. Thus, they have parents who use erratic and harsh disciplinary methods, which often escalate to physical abuse (Tas, 1996). Aggressive behaviour in humans is related to a number of physiological, psychological, familial, and cultural factors as well as the child's specific learning conditions (Huesmann, Eron, \& Klein, 1983). 
According to a national school crime survey, 7 percent of U.S. primary and secondary school teachers were threatened with injury, while 3 percent were physically attacked by a student from their own school between 2003 and 2004 (CHEN \& ASTOR, 2009). Other members of the school's staff were also potential victims; for example, another U.S. national study showed that over $75 \%$ of physical assaults or threats against school social workers were perpetrated by students (ibid).

In Chinese culture, teachers are highly revered professionals. Even now, teachers in Taiwan enjoy relatively higher prestige and job satisfaction than their international counterparts. Thus, students in Taiwan are expected to bow to their teachers as a mark of respect. Nevertheless, one study reported that 65.5 percent of surveyed junior high school teachers had been verbally assaulted by their students (ibid).

Consequently, student violence against teachers in Taiwan is a serious problem that requires the immediate attention of school administrators. However, there is no clear intervention program regarding student violence against teachers in Taiwan. These findings, based on representative data with all students from 4th to 12th grade in Taiwan, provide important evidence that can be used to establish policy on the prevention of student-on-teacher violence. Potential intervention programs in Taiwan may need to target male junior high school students (CHEN \& ASTOR, 2009).

Due to the fact that violence is one of the social issues that affect many Jordanian organizations, educational institutions are among the main sectors that have witnessed many incidences of violence over the past ten years. The public education system is established, supervised, and financed by the government. Thus, it includes the academic and vocational education branches, and the educational stages between class one (age six years) and class 12 (age 18 years) under the supervision of the Ministry of Education (MOE). The MOE is responsible for achieving the general objectives of education and supervising the educational organisations in Jordan. This is accomplished through educational legislation in ensuring high standards of education and educational facilities (AI-Zyoud, 2001). The MOE, however, has not implemented clear steps or actions to deal with the violence issue, either educationally or legally. As a result, schools and universities have been strongly involved in hundreds of violent incidents due to social and personal reasons. School violence may be defined as a forceful act or behaviour, such as assault, physical force, physical or psychological abuse or torture, hitting, or injury (Özdemir, 2012). School violence is "the intentional use of physical force or power, threatened or actual, against oneself, another person, or against a group or community that either results in or has a high 
likelihood of resulting in injury, death, psychological harm, maldevelopment, or deprivation" (ibid).

Violence in schools and universities can be defined procedurally as a pattern of offensive or compulsive behaviours, which include physical and psychological abuse of peers or teachers and the destruction of schools or university's property. However, school or university's student violence has emerged as a social and criminal problem in Jordanian society and universities (DAMRA \& GHBARI, 2014).

There have been relatively few studies on students' reports on why they perpetrate violence against school teachers (CHEN \& ASTOR, 2009). Majority of research has focused on the impact of student-on-student violence, whereas the impact of student-on-teacher violence has been relatively neglected (Galand, Lecocq, \& Philippot, 2007). Thus, this was despite its potentially serious consequences, e.g., teacher burnout and deteriorated teacher-student relationships (Wilson, Douglas, \& Lyon, 2011).

Teachers are the significant adults that provide students with knowledge and a safe environment for social and psychological development. Teachers are expected to be role models for school children and to be responsible for protecting students from harm as well as promoting student well-being (CHEN \& ASTOR, 2009). In return, students and parents are expected to give their full support to teachers, specifically by showing great respect to them and collaborating with them. However, the current situation is not acceptable in many schools due to the violence trend that occupies the educational scene. Violence negatively impacts teachers' mental health and teaching quality (Lyon \& Douglas, 1999; CHEN \& ASTOR, 2009). Violence in the Jordanian schools reached 100 incidents in 2015 (Mashaah, 2016).

In a national study in Taiwan with a sample that was representative of the entire student population from the 4th through 12th grades in Taiwanese schools, 30.1 percent of students reported being involved in, at least, one aggressive behaviour against teachers during the preceding twelve months (CHEN \& ASTOR, 2009).Violence in schools appeared in many forms. Harassment was the most frequent form of victimization. This was followed by property offenses and physical offenses. Students were the most common perpetrators of violence, but not the only perpetrators. Also, parents and colleagues also committed a substantial number of offenses. In addition, important trends in teacher victimization were found in terms of gender, race/ethnicity, and community setting. Thus, this sheds light on how teachers' experiences in schools vary (McMAHON et al., 2014). Physical punishment and school violence have a causal relationship in that the use of physical punishment increases the probability of violence in schools (Metin et al., 2014). 
Traditionally, Jordanian society gave teachers great value for their professional and ethical role. Jordanians generally had great respect and appreciation for teachers. Therefore, violence against teachers is considered to be completely unacceptable. Unfortunately, this situation no longer exists due to the lack of proper awareness of the support that teachers need in their profession. The lack of support from the official authorities has negatively affected the ideal image of teachers that the public had about them. In addition, irresponsible teachers have also damaged the image of teachers in Jordanian society.

Teacher professionalism is reflected when a society vests authority in teachers who accept responsibility for rendering particular expertise and service. Teacher professionalism, however, involves more than teaching subjects or implementing instructional methods and activities. Thus, it also encompasses the deeper understanding that teachers possess about how classrooms and schools are structured and why. Furthermore, it also entails how teaching and learning might be structured differently to better meet the needs of students and the society (Jesús et al., 2009).

The role of teachers is vital and essential. Teachers' behaviours are seen as role modelling and their positive behaviours will contribute significantly to the child's development (Metin et al., 2014).With the full understanding of the role of teachers towards future generations, violence against teachers has recently reached unacceptable levels. Therefore, this study tried to determine the reasons for student-on-teacher violence.

\section{Research Problem}

Violence against teachers is one of the challenging problems for the Jordanian educational system and Jordanian society. Teachers, parents, experts, the Teachers' Union, media, and the MOE have considered this issue to be a real threat to the dignity, respect, and the value of education in the Jordanian society. The number of violent cases against teachers reached 100 cases in 2015. Thus, these included assault, physical force, physical or psychological abuse, hitting, injury, and threatened deprivation.

Subsequently, this study tried to answer the following question: what are the reasons for students' violence against teachers in the Jordanian public schools, according to Jordanian high school students?

\section{Research Approach}

This study followed the qualitative approach by conducting interviews with the subjects of the study. Therefore, the strength of a qualitative research is its ability to provide complex textual descriptions of how people experience a given research issue. Qualitative research provides information about the "human" side of an issue - i.e., the often contradictory 
behaviours, beliefs, opinions, emotions, and relationships of individuals. Qualitative methods are also effective in identifying intangible factors, such as social norms, socioeconomic status, gender roles, ethnicity, and religion, whose role in the research issue may not be readily apparent (FAMILY HEALTH INTERNATIONAL, 2016).

In addition, the study adopted the qualitative research approach to reach a deep understanding of the reasons for violence against teachers from the perspective of high school students.

\section{Sampling}

The study followed the convenience sampling approach. This approach fits the nature of the study. Convenience (or opportunistic) sampling is a technique that uses an open period of recruitment that continues until a set number of subjects, events, or institutions are enrolled. Here, selection was based on a first-come, first-served basis. Therefore, this approach is used in studies that consider predefined populations (Health, 2016). Convenience sampling includes choosing the nearest individuals to serve as respondents and continuing that process until the required sample size has been obtained (Alzyoud, 2001). Qualitative researchers usually work with smaller samples of people in fewer global settings than survey researchers (Miles \& Huberman, 1984, cited in Alzyoud, 2001). For this reason, this study is not exceptional in generalising its qualitative results (interviews analysis) from a small sample of fifty high school students (25 boys and 25 girls) in grade twelve (AIzyoud, 2001).

The sample was selected from both public and private schools in the Zarqa and Amman educational directorates. However, these areas were selected due to the convenience of access to the researcher and the variety of student backgrounds, specifically schools from both rich and underprivileged areas.

\section{Data Analysis Approach}

The findings of the interviews with high school students are presented subsequently. The interview results are presented according to the source of the violence. Therefore, these sources are teachers, students, parents, and school administration.

\section{Definition of Terms}

Violence: Violence is an extreme form of aggression, such as assault, rape, or murder, with causes that include frustration, exposure to violent media, violence in the home or neighbourhood, and a tendency to see other people's actions as hostile even when they are not. Also, certain situations also increase the risk of aggression, such as drinking, insults, and other 
provocations and environmental factors, like heat and overcrowding (American Psychological Association, 2016).

Violence against Teachers: This refers to any form of physical and/or emotional abuse or unfair treatment of people that result in a real or potential danger of their health and dignity, i.e., harming their reputation (Lokmić, Opić, \& Bilić, 2013).

Grade Twelve Students: High school students aged eighteen years old that reached the last school grade.

\section{Importance of the Study}

This study is considered important for the following reasons: in Jordan.

It is the first study to explore the reasons for violence against teachers

The results of the study will help teachers, teachers' unions, and the MOE to deal with violence against teachers.

The study will enable parents to know the reasons behind violence against teachers from the perspective of students.

- $\quad$ It is the first study to examine violence against teachers from the perspective of students in Jordan.

- $\quad$ It is the first study to follow the qualitative approach in answering its questions.

\section{Findings and Discussion}

Interviews with fifty high school students showed that violence against teachers from students and parents was due to factors related to teachers, students, parents, and school administration. Therefore, both male and female students from all backgrounds showed similar justifications and reasons for violence against teachers.

Students stated that violence against teachers was due to teachers, school administration, the school environment, media, and family conditions. Teachers who receive violence from students are the cause of this violence due to their actions and practices. However, students were not the first to initiate or start having problems with teachers. Basically, the teachers were unable to accommodate students' needs, treat them in an unfriendly manner, and could not effectively communicate with students in helping them solve their problems. This is because only the classroom teachers have an educational background and can deal with students, both psychosocially and educationally. Also, subject matter teachers graduated without taking any educational courses, especially the courses that educate them about teaching methods, student psychology, and student needs. In addition, students believe that many teachers are not qualified to teach, graduated with the minimum score, and joined the profession without the desire to teach and 
deal with students. Furthermore, teachers in England enhance tolerance education through direct cooperation with international organizations, such as UNICEF. Their aim is to promote student's understanding of global citizenship and the children's rights as part of an intensive focus on how to be a good citizen both locally and internationally. Some schools have established partnerships with city councils and other schools to discuss issues related to tolerance and human rights from different perspectives, especially children from different backgrounds. However, doing so enhances student awareness, respect for others, as well as the importance of tolerating others (Al-Zyoud, Morgan, \& Brown, 2013).

Teachers are overloaded with heavy teaching loads and administrative duties. Also, teachers are exhausted and dispassionate. Therefore, they do not have the mood to communicate with students nicely or look into their problems and solve them. As a result, they have rigid ways of communicating and interacting with students, who find this unacceptable. Students usually react to teachers' practices using different forms of violence. The most common violence form is physical abuse. Currently, despite the presence of optimistic and enthusiastic teachers prepared to involve themselves in solving problems, there are also increased levels of frustration, since teachers are faced with extremely difficult tasks that they are scarcely qualified to deal with (Orpinas et al., 2004; Jesús et al., 2009). Subsequently, the elimination of these problems requires a series of actions for which there is currently no general formula, though the situation can be helped by the dissemination of all the accumulated knowledge on how to achieve an appropriate system of coexistence (Jesús et al., 2009).

Students are the cause of violence against teachers. Students do not have proper morals and discipline. Those students that have no respect for teachers and others have weak family ties and they mostly come from broken families. Their families are less educated, with poor communication and social skills. Therefore, they cannot communicate with teachers and their colleagues peacefully. Furthermore, schools do not teach morals and values properly. Students are exposed to the educational material and school curricula. Therefore, there is no room for extra school curricula and moral education that shapes students' personalities. Therefore, new generations have less respect for teachers and school and less commitment toward their society and country. Students are busy with social media, the internet, video games, and mobile apps, rather than morality and the values of their society. In September 2003, one of the TV stations broadcasted a video in which 17and 18-year-old students of a technical college in Torun harassed their teacher for an entire 45-minute English lesson. Thus, the video was recorded by one of the perpetrators. The teacher did not even try to leave the class. This was despite his desk being turned upside down, his bag and register 
book being stolen, students' physical aggression and threats, sex offers and sex simulations, constant oral aggression, attempts to deafen him by the noise of mobile phones, and the wastebasket being placed on his head (Kowzan, 2009).

Students exhibit violence against teachers as they are influenced by the videos they watch, online and internet happenings, and computer games. Most of such video games are based on action games and violence. Therefore, students often practice what they play and watch. This occurrence was also as a result of a lack of family supervision and control over what students watch and play. Media violence significantly increases the risk that a viewer or game player will behave more violently. Children automatically acquire scripts for the behaviours they observe around them in real life or in the media. Thus, this is along with emotional reactions and social cognitions that support those behaviours. Social comparison processes also lead children to seek out others who behave similarly aggressively in the media or in real life, leading to a downward spiral that increases the risk of violent behaviour (Huesmann \& Tversky, 2016).

Consequently, the lack of counselling and psychological support for students from certain backgrounds is another reason for violence against teachers. Until now, very few schools have had counselling and psychological support for students. Students need such services to accommodate their needs and solve their problems. Adolescent students have their own problems due to the nature of this stage. Hence, providing them with the required psychological support will enable them to communicate with others in a friendly manner. In this sense, students need peace education to enable them to acquire: a respect for life; a desire to end violence; the skills to promote and practice non-violence through education, dialogue, and cooperation; full respect for the principles of sovereignty, territorial integrity, and political independence of states and non-intervention in matters that exist essentially within the domestic jurisdiction of any state; full respect for/and the promotion of all human rights and fundamental freedoms; a commitment to the peaceful settlement of conflicts and efforts to meet the developmental and environmental needs of present and future generations; respect for/and the promotion of equal rights of/and opportunities for women and men; respect for/and the promotion of the rights of freedom of expression, opinion, and information for every person; and adherence to the principles of freedom, justice, democracy, tolerance, solidarity, cooperation, pluralism, cultural diversity, dialogue, and understanding at all levels of society and among nations (Al-Zyoud, Morgan, \& Brown, 2013).

School administrators are responsible for the violence against teachers. The administrators are unable to meet student's needs and cannot solve student problems. Administrators are teachers that were promoted 
because of their teaching experience. Thus, they were promoted not because they have the leadership skills that allow them to lead and focus on student conflicts, problems, and support. School leaders need to be prepared to have a positive and strong response to the drastic changes in educational systems. They will be able to support teachers and students if they were well-educated and qualified leaders. Administrators need to be well-equipped with the knowledge and skills of educational leadership, which would enable them to lead schools to be centres of excellence in teaching, learning, and building the capacities of students. In addition, it would move schools toward being learning communities for students and local community members. School leaders should have a wealth of experience with the educational process: teaching, learning, teachers' affairs, professional development, assessment and evaluation, curriculum design, strategic planning, school budgeting, and so on (Alzyoud, 2015). However, school administrators are challenged by the lack of resources and the lack of specialized and highly qualified human resources that lead and inspire followers, whether those followers are students, teachers, or principals (Alzyoud, 2009).

Violence against teachers occurs because of the large number of students in classes. Many schools have enormous enrolment due to the Syrian, Iraqi, and Yemeni crises. Hundreds of students from these countries have enrolled in public schools with limited space and available services. Students violate many things, not just the teachers. In addition, students do not enjoy their school life and experiences due to the huge numbers of students in classes. However, this situation has negatively affected students' interactions with each other as well as with their teachers. Schools are not equipped with the required educational facilities and resources, and they do not offer safe and secure environments for students. Teacher victimisation incurs significant costs, including lost wages, lost instructional time/productivity, increased workers' compensation, litigation, and negative publicity (Levin et al., 2006). Therefore, there is an urgent need to better understand the nature and extent of student-on-teacher violence to improve students' and teachers' experiences and make school systems safer and more effective (McMAHON et al., 2014).

Many teachers are old and the age gap between them and students is huge. Therefore, teachers have different interests and ways of thinking. Teachers do not seriously consider the new challenges and needs of students. As a result, this leads to misunderstanding between teachers and students due to the different views on educational and non-educational matters. Teachers who were raised through traditional educational approaches strongly believe in such approaches and they deny modern educational approaches and open channels of communication with their students. Therefore, such teachers show a lack of respect and humiliate their students. These teachers do not 
give any support to their students. As a result, students commit violence against teachers due to the lack of positive and friendly relationships with their teachers. Old teachers were considered as those who were burnt out and unable to find a common language with youth. From then on, it was often expressed that, simply, the wrong people are becoming teachers nowadays (Kowzan, 2009).

Another reason for the violence against teachers is because students are not taught social and educational morals, values, and ethics. Students come from different backgrounds; and oftentimes, they exhibit different attitudes toward teachers and schools. Schools have no formal educational subject about morals or ethics. Thus, this depends on the teachers and schools if they want to educate students and make them aware of their society's values and ethics. Teachers usually focus on educational and teaching subjects to cover the formal requirements.

Anyone that graduated with a bachelor's degree in a scientific educational subject is eligible to be a teacher. Hundreds of teachers graduated from high schools with the minimum entry requirement (65\%) to universities. After then, they graduated from universities with only a 2.00 grade point average. No scientific, robust selection process or test is required from teachers. Furthermore, hundreds of teachers graduated from noneducational colleges without any ideas about education, teaching methods, or learning. Hence, these teachers are not aware of how to deal with students' problems. Also, these teachers receive in-service educational training which is not enough to provide them with the educational knowledge that they need to be professional teachers. Therefore, teachers are not well-prepared to deal with students, both educationally and psychologically. Teachers can affect students' reactions as a result of their approaches and ways of working. Good preparation, interesting content presentation, and good communication with students, with specified boundaries of acceptable behaviour, together with the teacher being an example by creating a pleasant working atmosphere, will help prevent undesirable student behaviours (Lokmić, Opić, \& Bilić, 2013).

Students display violence against teachers because schools do not offer any educational co-curricular activities. Students throughout the academic year and the school day majorly focus on traditional educational activities. Students are surrounded with activities that are based on reading, writing, listening, and discussion. All the available activities are classroombased activities. Fine arts and physical education classes are not effective due to the lack of support from teachers, principals, and educational authorities. Thus, they consider these subjects to be unimportant. Most schools have no resources or facilities for these two subjects. Also, subject matter teachers always overtake these sessions to cover their own subjects. Furthermore, 
students have limited chances to leave their schools for educational, scientific, or leisure visits. Therefore, students spend their whole day and year without proper entertainment-based classes.

Students display violence against teachers due to the depression that students experience. Violent students are from poor, broken, and singleparent families. Students from such families are depressed. Often times, they imitate their parents and their experience outside school. Students are exposed to real violence in their families and environments. Therefore, they bring this violence to their schools. Students from such backgrounds lack the knowledge and skills of communication, interaction, positive thinking, tolerance, and dialogue. They strongly believe in physical and verbal violence, and often use them in handling their problems with teachers, principals, colleagues, and others.

Students display violence against teachers in response to the physically and psychologically aggressive acts that teachers shows toward them. Teachers of low personal, professional, educational, and scientific quality discriminate between students and use violence against them. Therefore, students react to teachers with the view of defending themselves.

Some students display violence against their teachers due to drug and alcohol problems. Students who take drugs and drink alcohol are not aware of the consequences of their acts. Thus, students from poor backgrounds have access to drugs and alcohol due to the lack of family supervision and care. These students have poor academic performance as well, which make teachers to react to these students with physical and verbal violence.

Furthermore, students strongly believe that students attack teachers due to the lack of proper legislation that would punish students that commit such crimes against their teachers. There is no specific legislation issued to protect teachers from student-on-teacher violence. When students commit violations, they seek help and support from their tribes. Thus, they benefit from societal traditions that enable tribe leaders to solve social problems without going to the police or courts. Many of these violations were handled by a visit from the tribe's leaders and the price for it was a cup of Arabic coffee. Students of such cultures usually get away with the crime they have committed.

The amount of violence that students experience through the media channels is massive. Consequently, students experience violence through computer games, console video games, YouTube, Twitter, television, Facebook, and many other sources. They watch and interact with all media channels, and this negatively affects their personalities. Moreover, the current conflicts and wars in many regional countries that surround Jordan affect students. The wars in Iraq, Syria, Yemen, Palestine, and Libya have changed students' perceptions about violence. Students have been strongly 
exposed to real fighting and killing scenes, which have affected their personalities. Basically, students have adopted some of what they saw in the media from the fighting and killing practices as their approach in dealing with their teachers, principals, and colleagues. This is internationally common. Here, an American speciality in the field of school violence is shooting. It has its own tradition, which means that perpetrators often refer to previous performances. One of the biggest shootings happened on the 17th of April 2007, when a 23-year-old student brought automatic pistols to the campus of Virginia Polytechnic Institute and State University, and killed 32 people (Jesús et al., 2009).

Students who attack their teachers bring violence and aggression from their families. Some students are part of aggressive family environments. The students have experienced violence between their parents, brothers, sisters, relatives, and neighbours. As such, they are very familiar with physical and verbal violence.

The socialization of students is limited to some family and religious duties and practices. Students have minimal interaction with parents and family members. In addition, students' life-styles have enhanced their selfcentredness. Parents are busy with their jobs and with other duties and responsibilities. They give minimal supervision and support to their children. Thus, students spend most of their time engaged in individual-based activities like video games, browsing the internet, listening to music, watching YouTube videos, and using their mobile devices. Such activities have affected their social skills and understanding of their culture. Violence has become part of their personalities and their ways of dealing with others and with problems due to their lack of social skills.

Schools are not the right place for some students. Students who commit violence against teachers are forced by parents to attend schools. Students find schools unattractive for various reasons related to poor school buildings, resources and culture, and low-quality teachers, principals, and colleagues. As a result, students hate schools under such conditions. They are unable to stay in school without making trouble and problems for others.

In some cases, parents, mainly fathers or male guardians, display violence against teachers in response to teachers' actions against their students. Parents react to teachers' practices and actions by displaying physical and verbal violence against them. Usually, such parents are not educated and come from poor families and underprivileged areas. They have poor communication skills and suffer from depression, frustration, and lack of respect in their communities. Therefore, they overreacted when they heard about teachers' violence or improper actions against their children. 


\section{Conclusion}

Violence against teachers is one of the main social issues that Jordanian society currently experiences. There are many factors behind this issue. High school students stated that students, parents, teachers, principals, and school culture were responsible for student-on-teacher violence. Therefore, violence against teachers occurred because of the following reasons:

Students commit violence against teachers because some teachers have low academic and educational performance. Schools are not the right places for some students. Therefore, some students are forced by their parents to attend schools. Students have minimal social interaction, typically few with family and religious duties. Some students are part of aggressive home environments. Students are not taught social and educational morals, values, and ethics. Also, there is no legislation that would punish students for committing such violence against teachers. Parents, mainly fathers or male guardians, commit violence against teachers in response to teachers' actions against their students.

\section{Recommendations}

The results of the study showed the needs for urgent actions to be taken by the educational authorities to eliminate the violence against teachers. Therefore, the study recommends the following:

- $\quad$ Provide teachers with the required educational training that would enable them to support their students and solve students’ problems.

- $\quad$ Provide schools with professional counsellors to help students to peacefully overcome their problems with teachers, colleagues, or others.

- Conduct educational training and workshops for students from underprivileged areas to enable them to communicate and interact with others peacefully.

- Improve the quality of the educational services, resources, and infrastructures that would help both teachers and students to work in a stressfree environment.

- $\quad$ Reduce the teaching loads of teachers to enable them to have enough time to help their students.

- $\quad$ Conduct more research on the causes of violence in schools from the perspectives of parents, teachers, and administrators.

\section{References:}

AI-Zyoud (2001). Academic Freedom, University Autonomy and Admission Policy in the Jordanian Public Universities. Nottingham: Nottingham University.

ALAIN (2000). Violence in School. European Education, 44-47. 
Alzyoud (2009). Twenty First Century Education Leadership (TFCEL) and its Challenges. London International Conference on Education (LICE-2009), UK (pp. 44-49). London: London International Conference on Education (LICE-2009), UK.

Alzyoud (2009). The Impact of Globalization on Jordan Society . Dirasat, Educational Sciences, Volume.

Alzyoud (2015). Educational Leaders and the Prospective Responsiveness to the Vast. International Education Studies; , 1-7.

Al-Zyoud, Morgan \& Brown (2013). Peace Education in English and Jordanian Schools: A Comparative Stud. Education Research and Perspectives , 211-235.

American Psychological Association. (2016, January 8). American Psychological Association. Retrieved from http://www.apa.org/topics/violence/

CHEN \& ASTOR (2009). Students’ Reports of Violence Against Teachers in Taiwanese Schools. Journal of School Violence, 2-17.

DAMRA \& GHBARI (2014). University Violence in Jordan: PTSD Consequences. Journal of Loss and Trauma, 364-374.

FAMILY HEALTH INTERNATIONAL (2016, January 8). Qualitative Research Methods: A Data Collector's Field Guide. Retrieved from Qualitative Research Methods Overview: http://www.ccs.neu.edu/course/is4800sp12/resources/qualmethods.pdf Ghate (2000). Family violence and Violence Against Children. CHILDREN \& SOCIETY, 395-403.

Gokler, Arslantas \& Unsal (2014). Prevalence of domestic violence and associated factors among married women in a semi-rural area of western Turkey. Pakistan Journal of Medical Sciences , 1087-1093.

Health (2016, January 8). Sampling in Qualitative Research. Retrieved from http://www.ncbi.nlm.nih.gov/pmc/articles/PMC3207270/

Hijazi (2009). Domestic Violence and Family Dysfunction as Risk Factor. Journal of Family Violence, 61-66.

Huesmann \& Tversky (2016, January 8). The Impact of Electronic Media Violence: Scientific Theory and Research. Retrieved from http://www.ncbi.nlm.nih.gov/pmc/articles/PMC2704015/

Huesmann, Eron \& Klein (1983). Mitigating the Imitation of Aggressive Behaviors by Changing Children's Attitudes About Media Violence. Journal of Personality and Social Psychology, 899-910.

Jesús et al. (2009). Teachers' perception of school violence in a sample from three european countries. European Journal of Psychology of Education, 4959. 
Kowzan (2009). Teachers and School Violence. A Comparative Study of Danish, American and Polish Phenomena. Journal of Alternative Perspectives in the Social Sciences , 736-747.

Rowell Huesmann (1983). Mitigating the Imitation of Aggressive Behaviors by Changing Children's Attitudes About Media Violence. Journal of Personality and Social Psychology, 899-910.

Lokmić, Opić \& Bilić (2013). VIOLENCE AGAINST TEACHERS- RULE OR EXCEPTION. International Journal of Cognitive Research in science, engineering and education.

Marsha \& Heather (2014). Violence against Canadian Women . Tornto: Centre for Research in Women's Healt.

Mashaah (2016, January 6). Violence in Schools. (Y. Televsion, Interviewer) Amman , Jordan.

MCMAHON et al. (2014). VIOLENCE DIRECTED AGAINST TEACHERS: RESULTS FROM A NATIONAL SURVEY. Psychology in the Schools, 753- 766.

Metin et al. (2014). The Development and Validation of the Teacher Violence Scale. Eurasian Journal of Educational Research, 69-88.

Okour \& Hijazi (2009). Domestic Violence and Family Dysfunction as Risk Factor for Violent Behavior among University Students in North Jorda. Family Violence, 361-366.

Özdemir (2012). An Investigation of Violence Against Teachers in Turkey. Journal of Instnjctional Psychology, 51-62.

Tas (1996). Youth and Violence in Europe. Studies on Crime and Crime Prevention, 31-58.

Tutkun \& Harman (2011). Attitude of Prospective Teachers' Towards Violence. International Online Journal of Educational Sciences, 67-78.

Wilson, Douglas \& Lyon (2011). Violence Against Teachers: Prevalence and Consequence. Journal of Interpersonal Violence , 2353 -237. 